\title{
Leptospirosis: risk factors and management challenges in developing countries
}

This article was published in the following Dove Press journal:

Research and Reports in Tropical Medicine

28 September 2016

Number of times this article has been viewed

\section{Cyrille Goarant}

Institut Pasteur International Network, Institut Pasteur in New Caledonia, Leptospirosis Research and Expertise Unit, Nouméa, New Caledonia
Correspondence: Cyrille Goarant Institut Pasteur International Network, Institut Pasteur in New Caledonia, Leptospirosis Research and Expertise Unit, BP6I, 98845 Nouméa cedex, New Caledonia

Tel +68727 753 I

Email cgoarant@pasteur.nc
Abstract: Leptospirosis is a widespread bacterial zoonosis with highest burden in low-income populations living in tropical and subtropical regions, both in urban and in rural environments. Rodents are known as the main reservoir animals, but other mammals may also significantly contribute to human infections in some settings. Clinical presentation of leptospirosis is nonspecific and variable, and most of the early signs and symptoms point to the so-called "acute fever of unknown origin", a major diagnostic challenge in tropical and subtropical areas. However, leptospirosis can rapidly evolve to life-threatening complications, especially if left untreated. There is a need for good awareness of leptospirosis and rapid antibiotic treatment based on clinical and epidemiological suspicion. Severe leptospirosis cases include renal and/or respiratory failure and shock, necessitating intensive care, also seldom available or with limited capacity. Confirmation of leptospirosis relies on biological diagnosis, which unfortunately uses tricky methods seldom available. This biological confirmation, however, is essential for surveillance and public health purpose. A good knowledge of leptospirosis epidemiology (eg, the reservoir animals involved, the Leptospira strains circulating, the seasonal and geographical patterns, and specific populations at risk) can be achieved through adequate surveillance and diagnosis. This can pave the way to prevention and intervention strategies and in turn alleviate the toll leptospirosis takes on affected populations. Over the past few years, leptospirosis has been increasingly recognized, as the need for multidisciplinary approaches in a One-Health perspective has been acknowledged, raising hope to successfully tackle the challenges of this zoonosis.

Keywords: leptospirosis, epidemiology, public health, treatment, prevention

\section{Introduction}

Leptospirosis is a zoonotic bacterial disease with a global distribution. Although its incidence is increasingly recognized in developed high-income countries, the highest burden is in tropical and subtropical regions worldwide, especially in developing countries. ${ }^{1}$ The natural history of leptospirosis, sometimes referred to as "leptospirosis cycle", determines its epidemiology. Pathogenic leptospires are maintained in the renal tubules of chronically infected asymptomatic mammals, mostly, though not exclusively, rodents. ${ }^{2}$ Bacteria are then shed through the urine of these animals in the environment, where they can survive for weeks to months in shaded, warm, and humid conditions. The conditions allowing the environmental survival of pathogenic leptospires largely determine the distribution of the disease, but human behavior also plays a role in both 
direct and indirect exposure. Animals get infected mostly through environmental exposure, but venereal transmission is also common in some mammal species. Humans get infected when they come into contact with these motile bacteria - through direct contact of skin lesions or mucous membranes with the urine of a carrier animal or, more frequently, through contact with freshwater bodies or watered soil contaminated by urine. Human-to-human transmission is exceptional. Leptospirosis takes a heavy toll in precarious and farming populations in developing countries from tropical and subtropical regions worldwide. In humans, leptospirosis first presents as an acute fever with headache and myalgia and accounts for one of the numerous possible etiologies of acute fevers in medical settings. If left untreated, it can degenerate into severe forms, with kidney and/or liver damage as well as severe pulmonary hemorrhage. Case fatality rates range from less than 5\% to more than 30\% depending on the clinical presentation and the case management. In developing countries, leptospirosis poses a number of challenges not only in the fields of public health (prevention and education, preparedness, intervention) but also in the fields of medical and biological diagnosis and case management.

\section{Leptospira: microbiology and taxonomy}

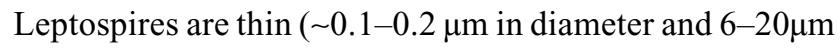
in length) helicoidal bacteria. The genus Leptospira, within Spirochaetes, now includes as many as 22 bacterial species. They are clustered in three subgroups (Figure 1) which correspond to their lifestyle. Saprophytes are normal inhabitants of freshwater environments. Pathogens are responsible for the infection of virtually any mammal species, in which they might cause the disease leptospirosis. Intermediates are able to infect mammals but usually display a lower virulence and only cause mild disease. Historically, leptospires were mostly classified according to their antigenic patterns into serovars (currently more than 250), clustered into more than 25 serogroups putting together antigenically related serovars. ${ }^{3}$ Unfortunately, the serological taxonomy does not correlate with the genetic taxonomy and some serogroups include strains from as many as six different bacterial species. However, because the epidemiology of leptospirosis was long studied with serological tools and because the reference serological technique ("A laboratory diagnosis challenge" section) identifies putative serogroups, the

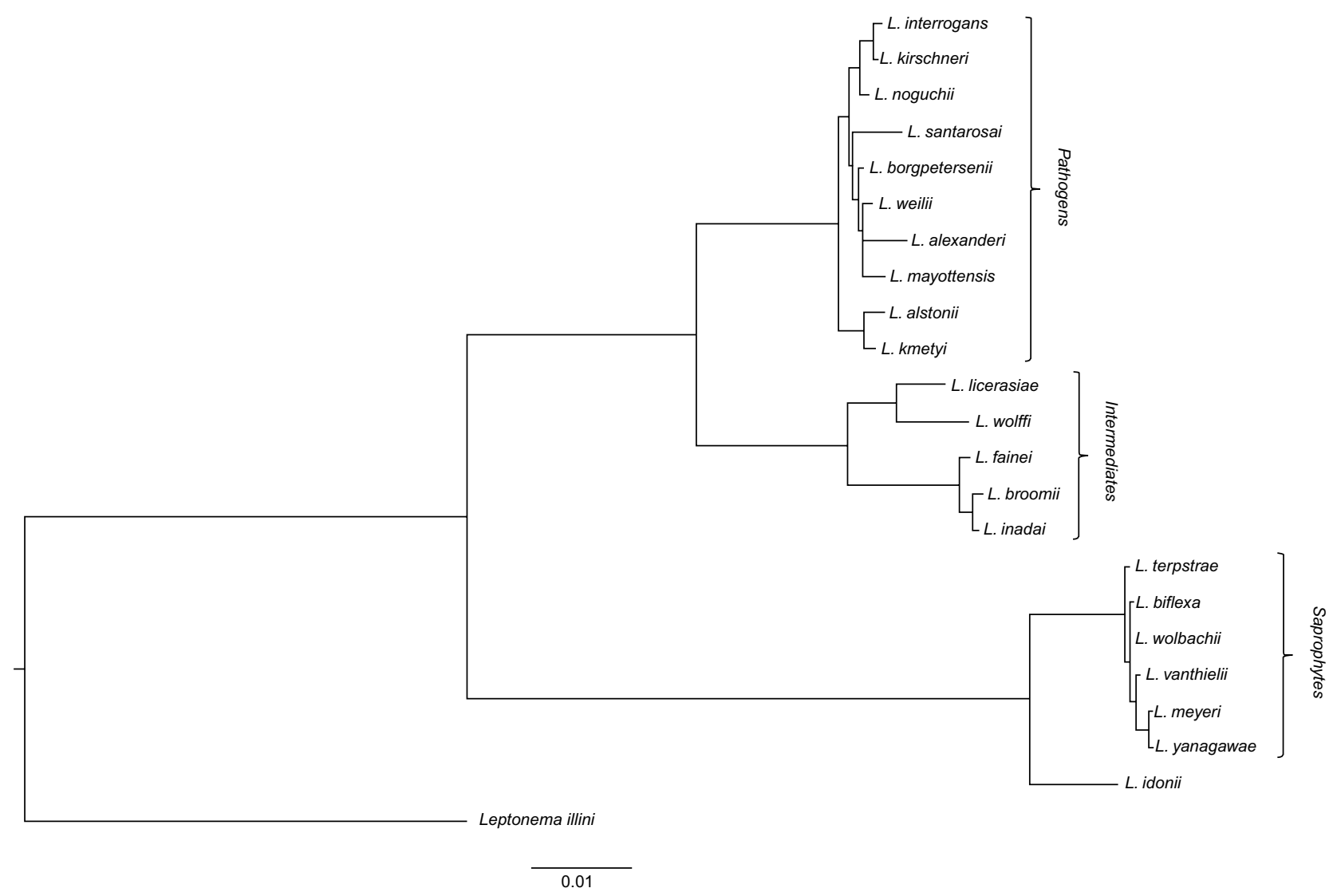

Figure I Molecular phylogeny of the genus Leptospira based on I6S rRNA sequences (neighbor joining method and Kimura's two-parameter distances). Note: The value 0.01 refers to one substitution per 100 nucleotides. 
serological taxonomy is still largely used. Current research notably aims at reconciling historical serology-based epidemiological knowledge with the current genetic taxonomy and molecular epidemiology tools.

\section{Risk factors of leptospirosis: rural and urban leptospirosis}

In temperate, high-income countries, leptospirosis was mostly an occupational disease, associated with freshwater or animal exposure. Sewage workers, butchers, farmers, veterinarians, or hunters were mostly exposed. It is now increasingly recognized as an environmental disease also associated with leisure activities (kayaking, rafting, canyoning, tramping, and other outdoor sports). ${ }^{4-6}$ A growing incidence is also recognized in people returning from holidays in tropical regions, also providing evidence of the environmental risk in the countries visited. ${ }^{7}$

\section{Animal reservoirs}

Animals are classically classified as maintenance or susceptible hosts. Following infection, susceptible hosts will usually develop a disease of variable severity, possibly leading to death. Those recovering will totally eliminate leptospires from their body in a matter of weeks. In contrast, maintenance hosts will develop no, or a mild, clinical disease. They will eliminate leptospires from their body except from the kidneys, where leptospires will persist and multiply for months in the proximal renal tubules. Populations of maintenance hosts are referred to as leptospirosis "reservoirs". However, an animal population might be a reservoir for a given Leptospira strain, whereas individuals might be susceptible to other Leptospira strains. The association between serovar Canicola and canine populations provides such an example, since dogs are regarded as highly susceptible to other leptospires. This particular reservoir association is thought to rely on some degree of coevolution and coadaptation, and the ultimate coadaptation is probably the evolution toward a parasite lifestyle, as is suggested in the association between serovar Hardjo and cattle. ${ }^{8}$ Frequent and widespread associations include rats and leptospires from the serogroup Icterohaemorrhagiae, mice and serogroup Ballum, dogs and serovar Canicola, cattle with serovar Hardjo, or pigs with serogroup Australis. A recent study in the paradigm leptospirosis reservoir Rattus norvegicus has also evidenced Leptospira in the breast tissue and milk of chronically infected females. ${ }^{9}$ Though the transmission of leptospirosis through lactation was already suggested, even in humans, ${ }^{10}$ chronic carriage and excretion through milk of reservoir hosts had not yet been evidenced. This finding might open new fields of research.

The animal reservoir in any given environment conditions the Leptospira strains involved in human cases. In rural contexts, a variety of Leptospira serovars are maintained and circulated from a number of mammals, including domestic animals like pigs, cattle, dogs, sheep, and goats. In contrast, in typical urban and peri-urban leptospirosis, rats (mainly Rattus norvegicus) carrying serogroup Icterohaemorrhagiae are the highly dominant reservoir.

\section{Domestic dogs acting as "vectors"}

The role of domestic dogs is somehow special. Though canine populations might be reservoirs of Leptospira from serovar Canicola, dogs are regarded as susceptible to other serovars. Dogs might be wandering in the environment where they come into contact with water and soils as well as directly with wild or feral mammals. They might become infected and shed leptospires in their urine from a few days to weeks, including in the close vicinity of their owners. In some regions where serovar Canicola was never evidenced, dogs might still contribute to human leptospirosis through this mechanism. ${ }^{11,12}$ They have, therefore, been proposed not only as sentinels reflecting the environmental contamination but also as possible "vectors" bringing wildlife leptospirosis closer to humans. ${ }^{11-14}$

\section{The environmental reservoir}

Upon excretion with the urine of infected animals, leptospires reach the environment. Pathogenic leptospires are considered to survive but not multiply in the environment. Pioneering works have delineated some physiological traits of Leptospira that condition their survival in the environment. ${ }^{15,16}$ It is usually recognized that pathogenic leptospires can survive in soils and freshwater bodies, including mud, swamps, streams, lakes and rivers, especially under neutral to slightly alkaline conditions. Pathogenic leptospires are notably known to be highly susceptible to ultraviolet light, chlorine, and detergents. ${ }^{16}$ They are also thought to be susceptible to acidic conditions and low temperature, but recent research suggests that these data should probably be revisited in multifactorial experimental designs or in situ, taking various Leptospira strains into consideration. ${ }^{17}$ Exposure to mud or stagnant freshwater might expose humans and animals to Leptospira. Typically, heavy rainfall washes superficial soils, bringing pathogenic leptospires in freshwater bodies, including floods, where humans will be exposed. Massive leptospirosis outbreaks usually emerge following floods after 
heavy rainfall, especially cyclones. Such outbreaks have been described in Nicaragua ${ }^{18}$ and the Philippines, ${ }^{19,20}$ for example, but seasonal peaks of high incidence also occur in many tropical regions like Thailand, ${ }^{21}$ or tropical islands. ${ }^{22,23}$ Of note, the ongoing climate change, by impacting rainfall patterns, will most probably impact leptospirosis distribution and incidence in a number of regions worldwide. ${ }^{24}$

Direct human infection from the animal reservoir happens especially in occupational contexts. Farmers, butchers, hunters, veterinarians, or rodent control workers, for example, might be exposed directly to the infected urine or kidneys. However, evidence suggests that indirect exposure through surface waters, soils, and mud largely predominates in human infections (Figure 2). Indirect environmental exposure also accounts for occupational exposures in farmers working in irrigated rice or taro paddies, in sugarcane or banana farms, freshwater fishermen, sewage workers, miners, soldiers, and farmers. Skin wounds and mucosae provide routes of entry for Leptospira into the body.

\section{Diagnostic challenges A protean clinical presentation: picking one in a thousand}

After a 2- to 21-day incubation, the onset is usually abrupt with fever, headache, and myalgia. Patients may, therefore, present with a classical flu-like syndrome. Interestingly, the schoolbook presentation of leptospirosis as Weil's disease with the triad of hemorrhage, jaundice, and renal failure was shown to account for less than one-third of confirmed leptospirosis cases. ${ }^{23}$ Similarly, the biphasic fever described earlier is not systematically observed; when it occurs, it is also late in the course of the disease (Figure 3). In tropical settings with numerous possible etiologies for acute fevers,

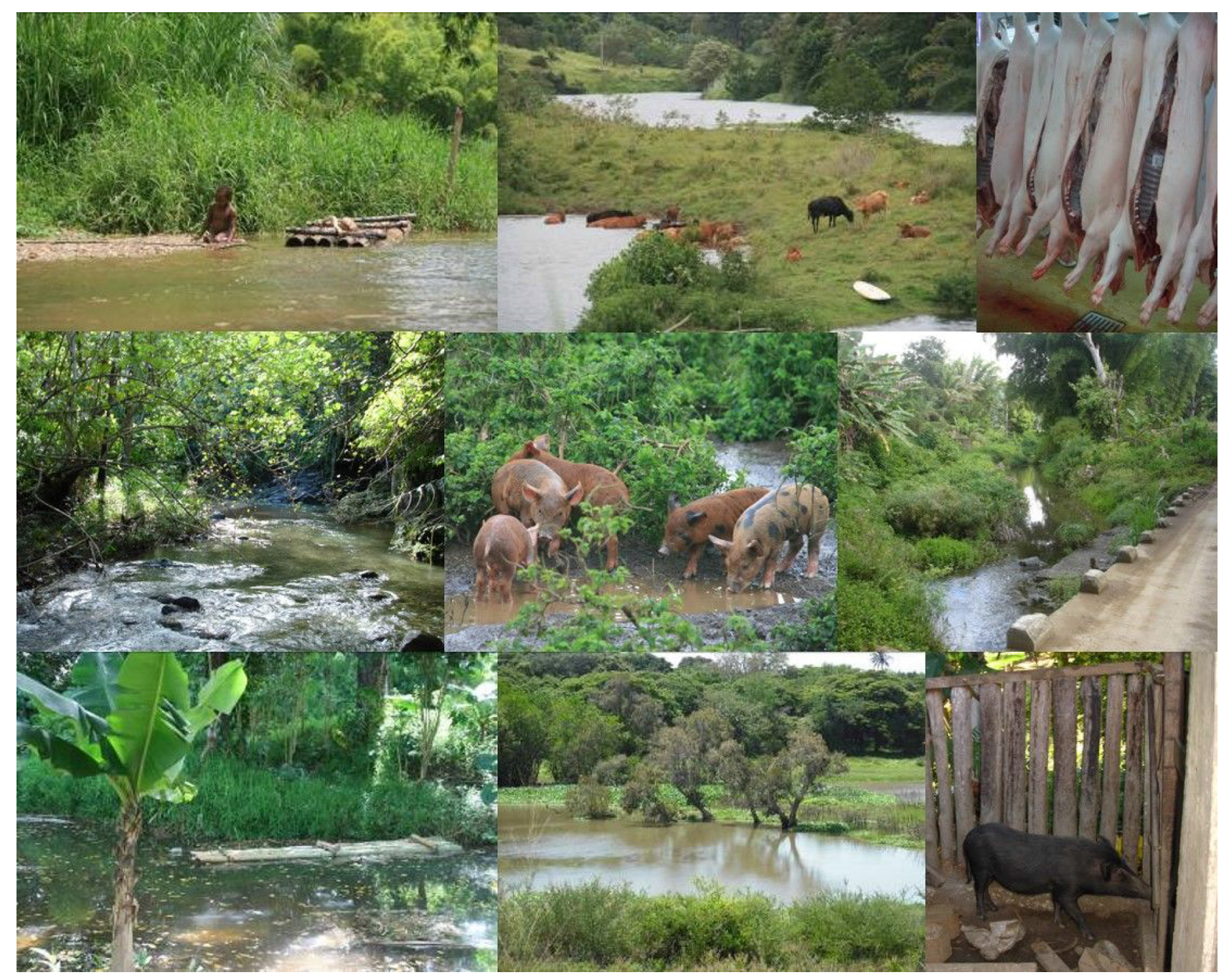

Figure 2 Examples of leptospirosis exposure settings taken in New Caledonia. 


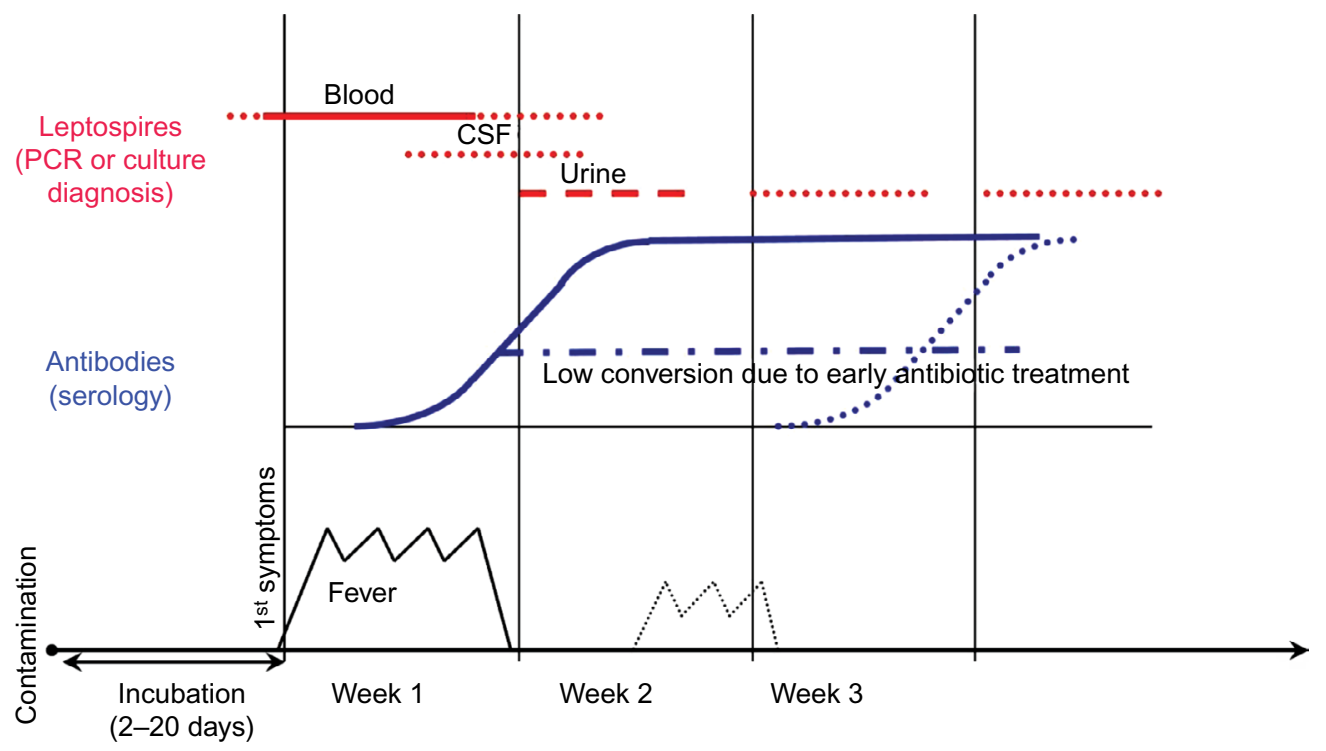

Figure 3 Basic principles underlying the biological diagnosis of leptospirosis.

Notes: Adapted from Turner. Leptospirosis I. Trans R Soc Trop Med Hyg. 1967;61 (6):842-855, ${ }^{124}$ by permission of Oxford University Press. Abbreviations: PCR, polymerase chain reaction; CSF, cerebrospinal fluid.

leptospirosis might be confused with malaria, influenza, dengue, scrub or murine typhus, spotted fevers, and a number of other possible viral, parasitic, or bacterial pathogens. ${ }^{25}$ In the particular context of dengue, yellow fever, or influenza outbreaks, leptospirosis might account for a few acute febrile cases among thousands. Because there is no pathognomonic sign or symptom, leptospirosis should be suspected on the basis of the epidemiological context and samples referred to the laboratory for biological investigation.

\section{A laboratory diagnosis challenge}

Within the first days of illness, reliable laboratory diagnosis of leptospirosis involves detecting Leptospira in biological fluids (Figure 3). This was historically achieved by culture, using the very particular culture medium EMJH (Ellinghausen and McCullough, modified by Johnson and Harris) ${ }^{26,27}$ and checking the cultures by dark-field microscopy for up to 14 weeks. Direct observation of motile helical-shaped bacilli in blood or urine has been used but is of low sensitivity; additionally, because of their tiny diameter, the specificity is very difficult to ascertain, so that this technique should be considered with much caution. Nowadays, nucleic acids amplification techniques are used with blood, urine, or cerebrospinal fluid as a matrix and targeting genes specific for pathogenic Leptospira. The advent of real-time polymerase chain reaction (PCR) has further accelerated the turnaround time and increased both sensitivity and specificity. A number of gene targets have been used for that purpose as well as different real-time PCR technologies, notably SYBR Green
$\mathrm{I}^{28-30}$ or hydrolysis (“TaqMan”) probes. ${ }^{31,32}$ However, real-time PCR platforms are not easily accessible, especially in remote or rural settings in developing countries, and these techniques require a high technical level. Constant-temperature amplification techniques, notably the loop-mediated isothermal amplification technique, have therefore been proposed for the detection of pathogenic Leptospira DNA $^{33,34}$ and these might be more suited to routine diagnosis in peripheral laboratory settings. Demonstrating the presence of Leptospira or its DNA in any of the biological fluids mentioned provides a definitive and certain diagnosis of leptospirosis. The kinetics of Leptospira in the infected body conditions the fluid to be analyzed; basically, leptospires might be found in the blood during the first week of symptoms but should rather be sought in the urine after this period (Figure 3). ${ }^{35}$

After a few days, the infected person mounts an immune response, which might also be evidenced in the laboratory (Figure 3). The reference serological technique is the microscopic agglutination test (MAT), which assesses the capacity of the patient serum to agglutinate live Leptospira among a battery of strains. The MAT positivity is known to arise after 1 week of onset of disease, notably later than immunoglobulin $\mathrm{M}(\mathrm{IgM})$. The infecting serogroup is supposedly represented by the serogroup of the strain which produces agglutination with the highest dilution of the serum. Though this epidemiological indication has a poor individual predictive value, it is still useful at the population level. ${ }^{36} \mathrm{~A}$ previous knowledge of the serogroups circulating in any given region allows adaptation of a panel of serovars to be included in the MAT analysis. 
Otherwise, a wide panel including as many serogroups as possible should be used for diagnosis. Because of the need to maintain live culture of numerous, possibly virulent, Leptospira strains, MAT is usually restricted to a small number of reference laboratories. Anti-Leptospira IgM antibodies are detectable early in the course of the disease, approximately at day 5. A number of tests are commercially available for this purpose, including enzyme linked immunosorbent assay (ELISA) and rapid lateral flow immuno-chromatography tests. The antigen mostly used in these assays is a killed culture of the saprophytic Leptospira biflexa, assumed to have a broad range of cross-reactivity with many (though not all $)^{37}$ serogroups. Recent work has suggested that other Leptospira strains might be more appropriate to be used as antigens for ELISA or rapid tests ${ }^{38,39}$ but are not commercially available. It is highly recommended to assess a seroconversion by showing an increase in IgM titers using a second, convalescent serum, especially in endemic regions where the population might be in frequent contact with leptospires and a basal anti-Leptospira immunity might be encountered. Despite allowing an easy detection in peripheral settings, it is highly recommended these results are confirmed using the MAT reference technique, ${ }^{40-43}$ both to eliminate possible false positives and to gain an insight into the infecting serogroup. Because not all rapid diagnostic tests perform equally in different epidemiological contexts, it is recommended that the introduction of these diagnostic techniques be done with support from reference centers with relevant expertise and using MAT cross-validation.

As a result, both direct diagnosis, by providing evidence of leptospires or their DNA, and indirect evidence, by demonstrating a specific immune response, require reference techniques that are usually not available in peripheral health centers where most leptospirosis cases might seek medical advice. The World Health Organization (WHO) and the International Leptospirosis Society, therefore, recommend that the patient be treated with antibiotics on the sole basis of a leptospirosis suspicion (clinical and epidemiological) and that biological specimens are referred to reference laboratories for confirmation. ${ }^{44}$

\section{Medical challenges}

A number of sero-prevalence surveys have shown that exposure to pathogenic Leptospira is very common in many tropical regions throughout the world.$^{45-50}$ Very interestingly, a recent survey in Brazil was aimed at evaluating leptospirosis sero incidence in a hyper-endemic area and paralleling this result with active surveillance data, thus allowing to evaluate the proportion of infections leading to clinical disease. ${ }^{51}$ The results of this study suggested that only a very small proportion of infections actually lead to clinical disease, with an estimate of as many as 191 infections for one clinical disease. This finding highlights that most leptospirosis cases spontaneously recover after a short febrile phase, if any. The precise Leptospira-host interactions clearly need further studies to better understand what triggers clinical disease in infected patients. Whether the frequent non-clinical infections by pathogenic leptospires in hyper-endemic contexts could lead to long-term detrimental health effects (possibly including chronic kidney lesions) $)^{52}$ or on the contrary provide some degree of herd immunity definitely deserves consideration. However, the following paragraphs address only the medical challenges of acute clinical leptospirosis.

\section{Medical management of severe cases}

As mentioned earlier, the first medical challenge is to include possible leptospirosis in the differential diagnosis of acute fevers. With regards to this challenge, taking the epidemiological context in consideration is of prime importance. Exposure to rodents and other mammals, surface waters, massive rainfall, as well as leisure or occupational activities can help point to the exposure risk of leptospirosis.

\section{Antibiotic treatment}

Despite minor differences in antibiotic susceptibility among Leptospira isolates, ${ }^{53}$ no acquired antibiotic resistance was ever demonstrated in Leptospira, and amoxicillin (or penicillin), tetracyclines, or ceftriaxone are successfully used in the treatment of leptospirosis. Systematic reviews failed to evidence a benefit of antibiotics, ${ }^{54}$ mostly because of a limited number of appropriate studies. ${ }^{55}$ However, field data show that an antibiotic treatment provided early is associated with a lower risk of severe disease ${ }^{56}$ at the individual level; at the population level, it was also suggested to lead to low severity and fatality rates ${ }^{57}$ as well as a financial benefit for the medical system. ${ }^{58}$ The WHO also recommends rapid presumptive antibiotic treatment, pointing to the empirical benefit of its introduction before the fifth day of disease. ${ }^{44}$ Penicillin or amoxicillin are usually recommended, but thirdgeneration cephalosporin, quinolones, or erythromycin are also used, and doxycycline is recommended in settings where other (possibly intracellular) bacteria might be involved. ${ }^{25,59}$ Among novel therapeutic approaches, the use of humanized monoclonal antibodies is a research subject currently being evaluated in animal models. ${ }^{60}$ 


\section{Intensive care and supportive treatment}

Most of the severe leptospirosis will require some degree of supportive treatment, including intensive care. The presentation frequently includes hemodynamic instability, requiring vasoactive drugs and intravenous therapy, which will also be used to give drugs and correct ion balance. Because patients frequently present with a septic shock and some degree of excessive inflammatory response is recognized, corticosteroids are sometimes used. However, there is still controversy about their efficiency and further studies are needed to evaluate their possible benefit. ${ }^{61}$ Non-steroidal anti-inflammatory drugs are usually not used, except in non-severe outpatients. Renal lesions may lead to acute renal failure; in this complication, the use of hemodialysis was shown to greatly improve outcome. ${ }^{62,63}$ In settings where hemofiltration is not available, peritoneal dialysis was also used successfully. ${ }^{64}$ Where neither can be implemented, oliguria caused by acute renal failure can rapidly lead to death. ${ }^{65}$ Hemorrhage can also be a major concern. A convenient access to a blood bank allows using packed red blood cells or platelets transfusion. A major leptospirosis complication which is increasingly recognized is the severe pulmonary hemorrhage. ${ }^{66}$ In this particular presentation, the blood and platelet transfusion alone cannot save the patient. The use of mechanical ventilation is of greatest help in addition to this transfusion treatment.

\section{Triage during massive or concurrent viral outbreaks}

As mentioned earlier, leptospirosis mostly occurs in tropical and subtropical regions, where a number of possible etiologies for acute fevers exist. In a context of limited hospital capacity, especially in intensive care units, there may be a need for patient triage. This stands particularly true in two situations: either during massive leptospirosis outbreaks following cyclones or during a concurrent (most frequently viral) outbreak. Massive viral outbreaks with patients requiring intensive care notably include dengue outbreaks. ${ }^{67}$ Due to difficult differential diagnosis, special attention should be paid to leptospirosis in this particular context of concurrent dengue fevers, ${ }^{68-71}$ also considering that coinfections occur. ${ }^{72,73}$ A number of clinical studies have been conducted in leptospirosis patients, aimed at identifying biological markers with a predictive value of severity. Though convincing differences were shown in some cohorts, there is currently no consensus on validated prognostic indicators in leptospirosis, and careful clinical examination mostly drives the decision to keep the patient hospitalized or treat him as an outpatient, with additional consideration being given to platelet counts and kidney function indicators (serum urea and creatinine) when available.

\section{Atypical cases and symptoms and delayed impact of leptospirosis}

Not only does leptospirosis present as a nonspecific acute fever but it might also be involved in other clinical presentations. These have been reviewed recently. ${ }^{74}$ A very good review of the medical presentations of leptospirosis is also included in Levett. ${ }^{35}$ Among the non-classical presentations, some are interesting reminders of the leptospirosis in animals. This includes uveitis which is a major concern in horses, but it is also relatively frequent in humans. Interestingly, uveitis is a delayed complication of leptospirosis, involving autoimmune mechanisms. ${ }^{75}$ Atypical leptospirosis in humans also includes miscarriage, a major concern in many domestic mammals which is possibly overlooked in humans. Cardiac manifestations mostly include arrhythmia, but myocarditis has also been frequently reported..$^{35}$ They usually occur during the acute phase; they might be considered as a sign pointing to possible leptospirosis in differential diagnosis. Neurological manifestations of leptospirosis might be seen in the acute phase, presenting as the so-called "aseptic meningitis". Delayed neurological complications might also present as Guillain-Barre syndrome. Lastly, another poorly recognized symptom in leptospirosis is represented by gastrointestinal manifestations; vomiting and diarrhea have been reported to be quite frequent in some leptospirosis cohorts..$^{35,65}$

\section{Leptospirosis: a public health challenge}

The diagnostic difficulties reported before, both at the medical and at the laboratory levels, significantly contribute to the underestimation of this disease in many countries. Early suspicion opens the way to efficient case management, greatly improving patient prognosis. For public health managers, the acknowledgement that this zoonotic and environmental disease is a concern, and an assessment of its scale, can help guide decisions affecting local or regional health priorities; veterinary public health policy; spatial planning politics in the field of land use, sewage, rainwater or waste management and the control of wild or stray animals.

\section{Case definition and surveillance system}

The WHO has issued "recommended surveillance standards" for leptospirosis in $1999,{ }^{76}$ later updated with the International Leptospirosis Society in 2003. ${ }^{44}$ This latter version 
(freely available online http://whqlibdoc.who.int/hq/2003/ WHO CDS CSR EPH 2002.23.pdf?ua=1, accessed May $19,2016)$ is based on a Questions and Answers (Q\&A) format, providing convenient guidelines for both the medical community and general population. The case definition is as follows: Acute febrile syndrom with headache, myalgia and prostration which may also include conjunctival suffusion, meningism, anuria/oliguria or proteinuria, icterus, hemorrhages, cardiac failure or arrhythmia, or skin rash in a patient with a history of possible exposure to an infected animal or environment with animal urine. Of note is the importance of the epidemiologic context with possible former risk exposure. The 2003 guidelines provide details about four typical clinical presentations, namely 1) mild influenza-like illness, 2) Weil's syndrome characterized by jaundice, renal failure, hemorrhage, and myocarditis with arrhythmias, 3) meningitis/meningoencephalitis, and 4) pulmonary hemorrhage with respiratory failure. These presentations may overlap during the course of the disease; however, this classification scheme highlights the fact that Weil's disease is only one out of a larger panel of possible clinical presentations.

The 1999 edition $^{76}$ recommends immediate reporting of suspected or confirmed cases from peripheral level to intermediate level with systematic investigation of all cases. In addition, routine reporting from intermediate to central level is recommended for all confirmed cases. The recommended collection of data includes geographic, demographic (including occupation), clinical, epidemiological, and meteorological data, all being useful to gain a good insight into the epidemiology of the disease: the age classes, occupations and exposure history (including possible heavy rain or floods), and the clinical presentation and outcome as well as microbiological and/or serological data. These latter data types can indicate a possible animal reservoir involved in the human cases being considered. In some countries, the notification is mandatory which greatly improves the surveillance efficiency. In contrast, in some places, there is no ad hoc surveillance system. The 2003 edition $^{44}$ also considers this frequent situation. In such cases, the occurrence of leptospirosis might be evidenced from biological samples, which might be collected from patients with an accordant clinical presentation, from known risk groups or randomly, and then submitted to a reference laboratory. A particular example is an outbreak of a disease resembling leptospirosis (already described in the sections "A protean clinical presentation: picking one in a thousand" and "Triage during massive or concurrent viral outbreaks"); in such situations, biological diagnosis allowing recognition of leptospirosis must be encouraged for prompt treatment to minimize aggravation in patients. This has already been reported, for example, during dengue outbreaks. ${ }^{67-71,77}$

Additional nonspecific surveillance schemes (eg, syndromic surveillance networks) might contribute to identify the start of an epidemic: abnormally high numbers of fevers of unknown origin, higher-than-average incidence of pulmonary hemorrhagic syndromes, or acute renal failures may, for example, be associated with an outbreak of leptospirosis.

A particular point must be raised in the field of surveillance: because human leptospirosis arises from animal reservoirs, attempts should be made to increase the collaboration between the veterinary and human public heath surveillance systems. Where possible, this might include the use of a common serovar panel for MAT analysis, comparisons of animal and human isolates, and regular information from the veterinary surveillance to inform human risk. As detailed earlier, canine leptospirosis, for example, might be a valuable indicator of environmental risk.

\section{A multifactorial disease}

The information gained from the surveillance is key to decision makers. Actually, this information helps identify leptospirosis risk: occupations, activities, areas, and/or seasons of highest incidence. Public health policy makers need to decide what the priorities should be. Depending on the context, this might include raising awareness in targeted populations, improving sewage networks or garbage collection systems, encouraging the use of personal protection equipment, or vaccinating risk groups. Because leptospirosis frequently affects low-income populations, the reduction of social inequities must also be considered as a way to decrease the burden of human leptospirosis. ${ }^{78,79}$

\section{Outbreak prediction}

In regions where leptospirosis is endemic, outbreaks might happen following heavy rainfall. Their prediction through risk modeling allows the public health system to be prepared. There are currently very few published models ${ }^{22,80}$ that can be used to reliably and timely predict leptospirosis outbreaks. Furthermore, one major limitation is the restricted geographical validity of such models, especially in continental areas. ${ }^{21,81}$ The major impact of the weather on leptospirosis epidemiology is well known, and heavy rainfall (eg, after cyclones) and floods are frequently linked with outbreaks. ${ }^{18-20,82,83}$ Seasonal fluctuations in rainfall (under the influence of the monsoon or inter-annual variations influenced by large-scale climate drivers like El Niño Southern Oscillation) frequently condition leptospirosis incidence. Rain intensity - either directly, 
by putting human and mammal populations in an environment prone to the survival of leptospires, or indirectly, by providing the rodent populations large amounts of food permitting population explosions - is a key factor in the prediction of leptospirosis epidemics. Therefore, future models for predicting leptospirosis outbreaks would surely be improved by integrating meteorological/climatic models, a research field that has made considerable progress in the past decades. As a second set of data feeding the models, rodent dynamics parameters (as the major leptospirosis reservoir) and their Leptospira carriage should probably be prioritized, which would most probably enhance the predictive capacity of such climate-based prediction models. ${ }^{84-86}$ These models are unfortunately rarely available even in endemic regions.

Another aspect of modeling is spatial mapping. The distribution of leptospirosis cases is known to be uneven and regions of highest incidence have been identified in a number of contexts. ${ }^{23,57,87-93}$ These efforts of leptospirosis mapping were also used to identify spatially associated risk factors. ${ }^{94-99}$ This geographical approach of risk mapping or risk identification through spatial analysis will most probably increase in the future and in turn help identify overlooked factors impacting leptospirosis incidence.

\section{Prevention, preparedness, and awareness}

Whether predicted by a validated model or even when no model has allowed pointing to a risk of higher incidence, preventive measures might be implemented before periods of highest risk, which might be known from seasonal fluctuations observed by the surveillance system. These might, for example, include rodent control programs and cleaning of river banks and sewage systems to minimize flood risk.

As discussed earlier, awareness is key to proper diagnosis and early treatment of leptospirosis. Preparedness, therefore, includes raising awareness of medical practitioners, especially in areas of highest incidence, but the awareness of high-risk groups identified by the surveillance scheme, of the general population where relevant, might also be considered useful.

The Queensland state of Australia, for example, has edited and disseminated occupation-specific recommendations for sugarcane, banana, and dairy industries using both leaflets and larger brochures. In La Reunion Island in the Indian Ocean, specific recommendations were drafted for school head teachers, which include specific compulsory rodent control actions around schools. In New Caledonia in the South Pacific, leptospirosis was included in the primary education program together with dengue and general hygiene education, and various leaflets, posters, and a board game are available in schools and holiday camps. In French Polynesia and La Reunion islands, specific awareness materials for children have been edited and distributed, notably using local languages or dialects.

In low-resource settings and general populations, including schools, the awareness messages are usually very simple and focus on minimizing infection risks ("do not go bare foot", "use boots and gloves to feed your backyard pig pen or to work in the field", "rapidly wash skin scratches or wounds with clear tap water and soap") and domestic rodents ("keep any food in closed containers", "eliminate uncollected fruits in your garden", "do not store garbage in open containers close to the house").

In all situations, health education and social mobilization must be adapted to the populations targeted and to the actual epidemiologic context, possibly integrating a multiplicity of reservoirs, places, periods, or activities putting humans at risk. The frequently seasonal pattern of leptospirosis might be used to better target awareness campaigns. Specific messages may be issued at the beginning of a hot rainy season or in the event of forecasted heavy rain, targeting both the general population and the medical community. The spread of leptospirosis factsheets in public areas might be used together with more specialized messages toward the medical community using professional journals.

The global scheme of human infection described earlier provides step by step indications on the possible preventive pathways. Preventive measures should focus on 1) limiting the mammal reservoir and 2) limiting human exposure. Besides rodent control programs that are unfortunately seldom implemented, any action aimed at minimizing the burden of animal leptospirosis is likely to minimize the risk of human infection. There is evidence (notably from New Zealand) suggesting that vaccination of farm animals might strongly contribute to lower occupational leptospirosis in farmers, veterinarians, slaughterhouse workers, and butchers. ${ }^{100,101}$ These vaccination campaigns have also raised awareness and encouraged the use of personal protection equipment. Though very successful, this New Zealand case study has not - to our knowledge - encouraged other regions or countries to conduct similar actions. Where available, the comparison of animal and human health surveillance data would provide indications as to which farm species should deserve consideration in priority.

Apart from lowering the importance of reservoirs, actions aimed at minimizing the exposure of humans to contaminated environments is prone to lower leptospirosis incidence. This 
very simple assessment has an incredibly high range of practical implications at almost any level of the society, from an individual to high-level political strategies. A better maintenance of sewage systems, notably avoiding open sewers; a better management of rubbish, notably collection networks; and avoiding open rubbish dumps are key examples of the issues to be considered at the political level. At regional or community level, any action leading to a reduced risk of flooding (like cleaning river banks) is likely to minimize human exposure to mud and surface waters. At the individual level, hygiene or protection measures in occupational, recreational, or "everyday life" contexts should also be considered.

\section{Outbreak response}

Responding to a leptospirosis outbreak first requires adequate care for patients who have been diagnosed with leptospirosis. An assessment of patients' conditions will allow triage of outpatients (who should be given antibiotics - either amoxicillin or doxycycline - and allowed to go) from inpatients, who will require hospitalization, thereby limiting medical overcrowding. The question of preventive mass chemoprophylaxis with doxycycline is still under debate and should be addressed very carefully from both the target population - restricted to limited populations at highest risk - and the drug dispatch system points of view ("The questions of vaccination and chemoprophylaxis" section). The best message toward the general population in such situations could be "earlier treated, better cured" or "the later, the more serious". The state of Queensland in Australia uses advice, "see a doctor straight away" together with a more frightening one, "If you delay, you may pay ... dearly". Whatever the words - that should be adapted to the target population - the message should be that any febrile syndrome should lead to visiting a doctor. Targeting the medical community, the message should emphasize the value of establishing an antibiotic treatment as soon as leptospirosis is suspected and before any lab confirmation can be achieved. This strategy, together with strong population awareness and rapid medical consultation, has been systematically implemented on Futuna (an island in the Wallis and Futuna archipelago in the South Pacific), where a very low case fatality rate of $0.5 \%$ was recorded for more than 400 cases. ${ }^{57}$

Understanding human infection mechanisms may also help reduce leptospirosis incidence in some ways. At the stage of an outbreak, there is no effective action to be taken on animal reservoirs. However, limiting human exposure to "lepto-friendly" environments may include accelerating the drop in flood water level by any practical way; prohibit bathing (or strongly advise not to bath) in places where cases were recently confirmed, recommend wearing of boots. Because of the emergency situation, direct media (like radio or TV) should be prioritized.

\section{The questions of vaccination and chemoprophylaxis}

As an infectious disease with possible fatal outcomes, the question of vaccination has to be considered. AntiLeptospira vaccines were developed very early after the isolation of the etiological agent of leptospirosis in Japan. After demonstrating successful protection in animals, a first large-scale vaccination of humans was conducted in Japan in 1919-1921, ${ }^{102}$ with significant success. ${ }^{65}$ These vaccines were made of heat-killed whole bacterial cells, so-called "bacterins", as are still the current vaccines licensed for human and animal use. However, there are major limitations to the widespread use of vaccination in humans. The protection conferred by vaccination is serovar specific (or at best serogroup specific) and of relatively short duration, with booster injections recommended yearly or at the very least every other year. These two limiting characteristics of leptospirosis vaccines need to be considered. First, the serovar of the vaccine strain must be the most significant from an epidemiological viewpoint; alternatively, polyvalent vaccines can also be designed (and are actually largely used in animal vaccination). ${ }^{103}$ This first limitation implies that in some epidemiological contexts, vaccinated people or animals might still develop leptospirosis if infected with a serovar with insufficient antigenic similarity with the vaccine strain. A good epidemiological knowledge of strains involved in human cases is therefore key before a decision on vaccination might be reached. Second, the short duration of immunity implies frequent (ideally yearly) boosters, a major limitation for implementation of large-scale vaccination of humans. In most contexts, it is therefore restricted to targeted populations, frequently in relation to recognized occupational risk. As described earlier, a large-scale vaccination of livestock was most probably linked to a dramatic decrease in occupational leptospirosis in New Zealand, ${ }^{100}$ an animal-based prevention strategy possibly contributing to reduce the burden of human disease. Interestingly, most studies on animal leptospirosis vaccines demonstrate that infections still occur in vaccinated animals, but do not evolve to severe disease and are associated with reduced or insignificant urinary shedding. ${ }^{104,105}$. The advent of large-scale genomic studies has also opened the field of reverse vaccinology approaches. Ongoing research aims at identifying proteins with the ability to provide a better 
protection, both against a large number of serogroups, of longer duration and providing sterilizing immunity in animals (reviewed and discussed in Adler ${ }^{102}$ ).

Chemoprophylaxis has also been considered as a way to protect humans from leptospirosis. ${ }^{106}$ This has mostly been applied to small groups of high-risk populations for short unavoidable exposures, like soldiers deployed in high risk areas, ${ }^{106}$ people involved in extreme outdoor sport events, ${ }^{5,107}$ or dairy farmers whose herds were shown to be heavily infected. ${ }^{108} \mathrm{~A}$ larger population in an endemic area was included in a randomized control trial. ${ }^{109}$ The chemoprophylaxis used in these trials was doxycycline and usually provided some degree of protection, against infection or preventing clinical disease or severity. A mass chemoprophylaxis campaign took place in Guyana in 2005, reaching an estimated 280,000 people, ${ }^{110}$ but the efficacy of this large campaign was difficult to assess. A Cochrane systematic review concluded that there was insufficient evidence of benefit to support the practice in all cases, though it might still be recommended to short-term travelers with a potential high risk of exposure. ${ }^{11}$

\section{Conclusion}

A recent systematic review and analysis has shed light on the neglected burden of leptospirosis. ${ }^{1}$ In addition to the current burden, there is evidence to suggest that climate change could lead to increase the incidence of leptospirosis, notably, but not only, in temperate regions. ${ }^{24,112}$ As already known, the estimated burden is highest in tropical and subtropical regions worldwide, but very major knowledge gaps remain, including regions where leptospirosis burden is estimated to be high. The lack of knowledge on leptospirosis burden is notably acknowledged in Central Asia, Southern Latin America, North Africa/Middle East, and almost all of Sub-Saharan Africa. ${ }^{1}$ A number of developing countries with lifestyle and climatic and ecological conditions prone to leptospirosis currently have no data on the real burden of this re-emerging zoonosis. Because of the nonspecific clinical presentation and tricky biological diagnosis, it might probably be overlooked in many of these countries.

However, there are a number of reasons for hope that leptospirosis will be increasingly considered and recognized, its surveillance improved, and in turn its burden alleviated by proper diagnosis and increased awareness. There is growing concern for leptospirosis in Africa, and current work is starting to increase our knowledge on the epidemiology and strains circulating in some African regions. ${ }^{113-121}$ The leptospirosis community has established the International
Leptospirosis Society ${ }^{122}$ to increase awareness and help implement appropriate biological diagnosis. More recently, the Global Leptospirosis Environmental Action Network (GLEAN) ${ }^{123}$ was created. Putting together not only researchers, clinicians, epidemiologists, laboratory biologists, veterinarians, public health policy makers but also climatologists, rodent ecologists, and modelers, it aims at developing or improving global and local strategies of how to predict, prevent, detect, and control leptospirosis outbreaks in a OneHealth approach. This initiative, besides its own goals, is also convincing evidence that the challenges of leptospirosis need synergizing of the knowledge and skills from a number of disciplines. It is encouraging proof of a growing interest in leptospirosis and that a number of people with their own skills around the world are ready to collaborate and commit themselves to take up these challenges.

\section{Acknowledgments}

This work was done as part of the activities of GLEAN, whose main purpose is to help countries in developing and implementing policies and tools for leptospirosis management. Thanks are due to the medical staff for their commitment to not neglecting leptospirosis and to the laboratory staff and the medical biologists at Institut Pasteur in New Caledonia.

\section{Disclosure}

The author reports no conflicts of interest in this work.

\section{References}

1. Costa F, Hagan JE, Calcagno J, et al. Global morbidity and mortality of leptospirosis: a systematic review. PLoS Negl Trop Dis. 2015;9(9):e0003898.

2. Adler B, de la Pena Moctezuma A. Leptospira and leptospirosis. Vet Microbiol. 2009;140(3-4):287-296.

3. Levett PN. Systematics of leptospiraceae. Curr Top Microbiol Immunol. 2015;387:11-20.

4. Brockmann S, Piechotowski I, Bock-Hensley O, et al. Outbreak of leptospirosis among triathlon participants in Germany, 2006. BMC Infect Dis. 2010;10:91.

5. Haake DA, Dundoo M, Cader R, et al. Leptospirosis, water sports, and chemoprophylaxis. Clin Infect Dis. 2002;34(9):e40-e43.

6. Morgan J, Bornstein SL, Karpati AM, et al. Outbreak of leptospirosis among triathlon participants and community residents in Springfield, Illinois, 1998. Clin Infect Dis. 2002;34(12):1593-1599.

7. Goris MGA, Boer KR, Duarte TATE, Kliffen SJ, Hartskeerl RA. Human leptospirosis trends, the Netherlands, 1925-2008. Emerg Infect Dis. 2013;19(3):371-378.

8. Bulach DM, Zuerner RL, Wilson P, et al. Genome reduction in Leptospira borgpetersenii reflects limited transmission potential. Proc Natl Acad Sci U S A. 2006;103(39):14560-14565.

9. De Oliveira D, Figueira CP, Zhan L, et al. Leptospira in breast tissue and milk of urban Norway rats (Rattus norvegicus). Epidemiol Infect. 2016;28:1-10.

10. Bolin CA, Koellner P. Human-to-human transmission of Leptospira interrogans by milk. J Infect Dis. 1988;158(1):246-247. 
11. Weekes CC, Everard CO, Levett PN. Seroepidemiology of canine leptospirosis on the island of Barbados. Vet Microbiol. 1997;57(2-3):215-222.

12. Gay N, Soupé-Gilbert ME, Goarant C. Though not reservoirs, dogs might transmit Leptospira in New Caledonia. Int J Environ Res Public Health. 2014;11(4):4316-4325.

13. Millan J, Candela MG, Lopez-Bao JV, Pereira M, Jimenez MA, Leon-Vizcaino L. Leptospirosis in wild and domestic carnivores in natural areas in Andalusia, Spain. Vector Borne Zoonotic Dis. 2008;9(5):549-554.

14. Koizumi N, Muto MM, Akachi S, et al. Molecular and serological investigation of Leptospira and leptospirosis in dogs in Japan. J Med Microbiol. 2013;62(Pt 4):630-636.

15. Faine S. Guidelines for the Control of Leptospirosis. Geneva: World Health Organization; 1982.

16. Faine S, Adler B, Bolin C, Perolat P. Leptospira and Leptospirosis.2nd ed. Melbourne, Australia: MedSci; 1999.

17. Andre-Fontaine G, Aviat F, Thorin C. Waterborne leptospirosis: survival and preservation of the virulence of pathogenic Leptospira spp. in fresh water. Curr Microbiol. 2015;71(1):136-142.

18. Trevejo RT, Rigau-Perez JG, Ashford DA, et al. Epidemic leptospirosis associated with pulmonary hemorrhage-Nicaragua, 1995. J Infect Dis. 1998;178(5):1457-1463.

19. Easton A. Leptospirosis in Philippine floods. BMJ. 1999;319(7204):212.

20. Amilasan AT, Ujiie M, Suzuki M, et al. Outbreak of leptospirosis after flood, the Philippines, 2009. Emerg Infect Dis. 2012;18(1):91-94.

21. Chadsuthi S, Modchang C, Lenbury Y, Iamsirithaworn S, Triampo W. Modeling seasonal leptospirosis transmission and its association with rainfall and temperature in Thailand using time-series and ARIMAX analyses. Asian Pac J Trop Med. 2012;5(7):539-546.

22. Desvars A, Jego S, Chiroleu F, Bourhy P, Cardinale E, Michault A. Seasonality of human leptospirosis in Reunion Island (Indian Ocean) and its association with meteorological data. PLoS One. 2011;6(5):e20377.

23. Goarant C, Laumond-Barny S, Perez J, Vernel-Pauillac F, Chanteau S, Guigon A. Outbreak of leptospirosis in New Caledonia: diagnosis issues and burden of disease. Trop Med Int Health. 2009;14(8):926-929.

24. Lau CL, Smythe LD, Craig SB, Weinstein P. Climate change, flooding, urbanisation and leptospirosis: fuelling the fire? Trans $R$ Soc Trop Med Hyg. 2010;104(10):631-638.

25. Mayxay M, Sengvilaipaseuth O, Chanthongthip A, et al. Causes of fever in rural Southern Laos. Am J Trop Med Hyg. 2015;93(3):517-520.

26. Ellinghausen $\mathrm{HC} \mathrm{Jr}$, McCullough WG. Nutrition of Leptospira pomona and growth of 13 other serotypes: fractionation of oleic albumin complex and a medium of bovine albumin and polysorbate $80 . \mathrm{Am} \mathrm{J}$ Vet Res. 1965;26:45-51.

27. Johnson RC, Harris VG. Differentiation of pathogenic and saprophytic Leptospires. I. Growth at low temperatures. J Bacteriol. 1967;94(1):27-31.

28. Merien F, Portnoi D, Bourhy P, Charavay F, Berlioz-Arthaud A, Baranton G. A rapid and quantitative method for the detection of Leptospira species in human leptospirosis. FEMS Microbiol Lett. 2005;249(1):139-147.

29. Levett PN, Morey RE, Galloway RL, Turner DE, Steigerwalt AG, Mayer LW. Detection of pathogenic leptospires by real-time quantitative PCR. J Med Microbiol. 2005;54(Pt 1):45-49.

30. Ahmed A, Engelberts MF, Boer KR, Ahmed N, Hartskeerl RA. Development and validation of a real-time PCR for detection of pathogenic Leptospira species in clinical materials. PLoS One. 2009;4(9):e7093.

31. Stoddard RA, Gee JE, Wilkins PP, McCaustland K, Hoffmaster AR. Detection of pathogenic Leptospira spp. through TaqMan polymerase chain reaction targeting the LipL32 gene. Diagn Microbiol Infect Dis. 2009;64(3):247-255.

32. Smythe LD, Smith IL, Smith GA, et al. A quantitative PCR (TaqMan) assay for pathogenic Leptospira spp. BMC Infect Dis. 2002;2:13.

33. Sonthayanon P, Chierakul W, Wuthiekanun V, et al. Accuracy of loopmediated isothermal amplification for diagnosis of human leptospirosis in Thailand. Am J Trop Med Hyg. 2011;84(4):614-620.
34. Chen HW, Weissenberger G, Atkins E, Chao CC, Suputtamongkol Y, Ching WM. Highly sensitive loop-mediated isothermal amplification for the detection of Leptospira. Int J Bact. 2015;2015:147173.

35. Levett PN. Leptospirosis. Clin Microbiol Rev. 2001;14(2):296-326.

36. Levett PN. Usefulness of serologic analysis as a predictor of the infecting serovar in patients with severe leptospirosis. Clin Infect Dis. 2003;36(4):447-452.

37. Picardeau M, Cornet M, Morel V, et al. Impact of the revised diagnostic policy on the diagnosis and surveillance of leptospirosis in France. Bull Epidémiol Hebd. 2008;37:329-331.

38. Bourhy P, Vray M, Picardeau M. Evaluation of an in-house ELISA using the intermediate species Leptospira fainei for diagnosis of leptospirosis. J Med Microbiol. 2013;62(Pt 6):822-827.

39. Goarant C, Bourhy P, D'Ortenzio E, et al. Sensitivity and specificity of a new vertical flow rapid diagnostic test for the serodiagnosis of human leptospirosis. PLoS Negl Trop Dis. 2013;7(6):e2289.

40. Winslow WE, Merry DJ, Pirc ML, Devine PL. Evaluation of a commercial enzyme-linked immunosorbent assay for detection of immunoglobulin M antibody in diagnosis of human leptospiral infection. $J$ Clin Microbiol. 1997;35(8):1938-1942.

41. Cumberland P, Everard CO, Levett PN. Assessment of the efficacy of an IgM-elisa and microscopic agglutination test (MAT) in the diagnosis of acute leptospirosis. Am J Trop Med Hyg. 1999;61(5):731-734.

42. Levett PN, Branch SL, Whittington CU, Edwards CN, Paxton H. Two methods for rapid serological diagnosis of acute leptospirosis. Clin Diagn Lab Immunol. 2001;8(2):349-351.

43. Picardeau M, Bertherat E, Jancloes M, Skouloudis AN, Durski K, Hartskeerl RA. Rapid tests for diagnosis of leptospirosis: Current tools and emerging technologies. Diagn Microbiol Infect Dis. 2014;78(1):1-8.

44. World Health Organization (WHO), International Leptospirosis Society (ILS). Human Leptospirosis: Guidance for Diagnosis, Surveillance and Control. Geneva: World Health Organization; 2003.

45. Van CT, Thuy NT, San NH, Hien TT, Baranton G, Perolat P. Human leptospirosis in the Mekong delta, Viet Nam. Trans R Soc Trop Med Hyg. 1998;92(6):625-628.

46. Sehgal SC, Vijayachari P, Murhekar MV, Sugunan AP, Sharma S, Singh SS. Leptospiral infection among primitive tribes of Andaman and Nicobar Islands. Epidemiol Infect. 1999;122(3):423-428.

47. Vado-Solis I, Cardenas-Marrufo MF, Jimenez-Delgadillo B, et al. Clinical-epidemiological study of leptospirosis in humans and reservoirs in Yucatan, Mexico. Rev Inst Med Trop Sao Paulo. 2002;44(6): 335-340.

48. Johnson MA, Smith H, Joeph P, et al. Environmental exposure and leptospirosis, Peru. Emerg Infect Dis. 2004;10(6):1016-1022.

49. Kawaguchi L, Sengkeopraseuth B, Tsuyuoka R, et al. Seroprevalence of leptospirosis and risk factor analysis in flood-prone rural areas in Lao PDR. Am J Trop Med Hyg. 2008;78(6):957-961.

50. Schoonman L, Swai ES. Risk factors associated with the seroprevalence of leptospirosis, amongst at-risk groups in and around Tanga city, Tanzania. Ann Trop Med Parasitol. 2009;103(8):711-718.

51. Felzemburgh RD, Ribeiro GS, Costa F, et al. Prospective study of leptospirosis transmission in an urban slum community: role of poor environment in repeated exposures to the leptospira agent. PLoS Negl Trop Dis. 2014;8(5):e2927.

52. Yang HY, Hung CC, Liu SH, et al. Overlooked risk for chronic kidney disease after leptospiral infection: a population-based survey and epidemiological cohort evidence. PLoS Negl Trop Dis. 2015;9(10):e0004105.

53. Wuthiekanun V, Amornchai P, Paris DH, et al. Rapid isolation and susceptibility testing of Leptospira spp. using a new solid medium (LVW agar). Antimicrob Agents Chemother. 2013;57(1):297-302.

54. Charan J, Saxena D, Mulla S, Yadav P. Antibiotics for the treatment of leptospirosis: systematic review and meta-analysis of controlled trials. Int J Prev Med. 2013;4(5):501-510.

55. Brett-Major DM, Coldren R. Antibiotics for leptospirosis. Cochrane Database Syst Rev. 2012;2:CD008264. 
56. Tubiana S, Mikulski M, Becam J, et al. Risk factors and predictors of severe leptospirosis in New Caledonia. PLoS Negl Trop Dis. 2013;7(1):e1991.

57. Massenet D, Yvon JF, Couteaux C, Goarant C. An unprecedented high incidence of leptospirosis in Futuna, South Pacific, 2004-2014, evidenced by retrospective analysis of surveillance data. PLoS One. 2015;10(11):e0142063.

58. Suputtamongkol Y, Pongtavornpinyo W, Lubell Y, et al. Strategies for diagnosis and treatment of suspected leptospirosis: a cost-benefit analysis. PLoS Negl Trop Dis. 2010;4(2):e610.

59. Dittrich S, Rattanavong S, Lee SJ, et al. Orientia, rickettsia, and leptospira pathogens as causes of CNS infections in Laos: a prospective study. Lancet Glob Health. 2015;3(2):e104-e112.

60. Maneewatch S, Sakolvaree Y, Tapchaisri P, et al. Humanizedmonoclonal antibody against heterologous Leptospira infection. Protein Eng Des Sel. 2009;22(5):305-312.

61. Rodrigo C, Lakshitha de Silva N, Goonaratne R, et al. High dose corticosteroids in severe leptospirosis: a systematic review. Trans $R$ Soc Trop Med Hyg. 2014;108(12):743-750.

62. Andrade L, Cleto S, Seguro AC. Door-to-dialysis time and daily hemodialysis in patients with leptospirosis: impact on mortality. Clin J Am Soc Nephrol. 2007;2(4):739-744.

63. Seguro AC, Andrade L. Pathophysiology of leptospirosis. Shock. 2013;39(Suppl 1):17-23.

64. Ooi BS, Chen BT, Tan KK, Khoo OT. Human renal leptospirosis. Am J Trop Med Hyg. 1972;21(3):336-341.

65. Haake DA, Levett PN. Leptospirosis in humans. Curr Top Microbiol Immunol. 2015;387:65-97.

66. Ko AI, Goarant C, Picardeau M. Leptospira: the dawn of the molecular genetics era for an emerging zoonotic pathogen. Nat Rev Microbiol. 2009;7(10):736-747.

67. LaRocque RC, Breiman RF, Ari MD, et al. Leptospirosis during dengue outbreak, Bangladesh. Emerg Infect Dis. 2005;11(5):766-769.

68. Ellis T, Imrie A, Katz AR, Effler PV. Underrecognition of leptospirosis during a dengue fever outbreak in Hawaii, 2001-2002. Vector Borne Zoonotic Dis. 2008;8(4):541-547.

69. Brown MG, Vickers IE, Salas RA, Smikle MF. Leptospirosis in suspected cases of dengue in Jamaica, 2002-2007. Trop Doct. 2010;40(2):92-94.

70. Sanders EJ, Rigau-Perez JG, Smits HL, et al. Increase of leptospirosis in dengue-negative patients after a hurricane in Puerto Rico in 1996 [correction of 1966]. Am J Trop Med Hyg. 1999;61(3):399-404.

71. Lindo J, Brown PD, Vickers I, Brown M, Jackson ST, Lewis-Fuller E. Leptospirosis and malaria as causes of febrile illness during a dengue epidemic in Jamaica. Pathog Glob Health. 2013;107(6):329-334.

72. Sharp TM, Bracero J, Rivera A, et al. Fatal human co-infection with Leptospira spp. and dengue virus, Puerto Rico, 2010. Emerg Infect Dis. 2012;18(5):878-880.

73. Perez Rodriguez NM, Galloway R, Blau DM, et al. Case series of fatal Leptospira spp./dengue virus co-infections - Puerto Rico, 2010-2012. Am J Trop Med Hyg. 2014;91(4):760-765.

74. Rajapakse S, Rodrigo C, Balaji K, Fernando SD. Atypical manifestations of leptospirosis. Trans R Soc Trop Med Hyg. 2015;109(5):294-302.

75. Verma A, Kumar P, Babb K, Timoney JF, Stevenson B. Cross-reactivity of antibodies against leptospiral recurrent uveitis-associated proteins A and B (LruA and LruB) with eye proteins. PLoS Negl Trop Dis. 2010;4(8):e778.

76. World Health Organization (WHO). WHO Recommended Standards and Strategies for Surveillance Prevention and Control of Communicable Diseases: Leptospirosis. Vol WHO/CDS/CSR/ISR/99.2. Geneva: World Health Organization; 1999.

77. Gamboa AA, Vasco L, Espinel M, Coloma J, Trueba G. Difficulties in the differential diagnosis of dengue and leptospirosis in Guayaquil. Av Cienc Ing. 2013;5(1):B10-B13.

78. Reis RB, Ribeiro GS, Felzemburgh RD, et al. Impact of environment and social gradient on leptospira infection in urban slums. PLoS Negl Trop Dis. 2008;2(4):e228.
79. Ernst KC, Phillips BS, Duncan BD. Slums are not places for children to live: vulnerabilities, health outcomes, and possible interventions. Adv Pediatr. 2013;60(1):53-87.

80. Weinberger D, Baroux N, Grangeon J-P, Ko AI, Goarant C. El Niño Southern Oscillation and leptospirosis outbreaks in New Caledonia. PLoS Negl Trop Dis. 2014;8(4):e2798.

81. Guimaraes RM, Cruz OG, Parreira VG, Mazoto ML, Vieira JD, Asmus CI. [Temporal analysis of the relationship between leptospirosis and the occurrence of flooding due to rainfall in the city of Rio de Janeiro, Brazil, 2007-2012]. Cien Saude Colet. 2014;19(9):3683-3692.

82. Kouadio IK, Aljunid S, Kamigaki T, Hammad K, Oshitani H. Infectious diseases following natural disasters: prevention and control measures. Expert Rev Antiinfect Ther. 2012;10(1):95-104.

83. Su HP, Chan TC, Chang CC. Typhoon-related leptospirosis and melioidosis, Taiwan, 2009. Emerg Infect Dis. 2011;17(7):1322-1324.

84. Holt J, Davis S, Leirs H. A model of leptospirosis infection in an African rodent to determine risk to humans: seasonal fluctuations and the impact of rodent control. Acta Trop. 2006;99(2-3):218-225.

85. Perez J, Brescia F, Becam J, Mauron C, Goarant C. Rodent abundance dynamics and leptospirosis carriage in an area of hyper-endemicity in New Caledonia. PLoS Negl Trop Dis. 2011;5(10):e1361.

86. Panti-May JA, Carvalho-Pereira TS, Serrano S, et al. A two-year ecological study of Norway rats (Rattus norvegicus) in a Brazilian urban slum. PLoS One. 2016;11(3):e0152511.

87. Garcia-Ramirez LM, Giraldo-Pulgarin JY, Agudelo-Marin N, et al. Geographical and occupational aspects of leptospirosis in the coffeetriangle region of Colombia, 2007-2011. Recent Pat Antiinfect Drug Discov. 2015;10(1):42-50.

88. Svircev Z, Markovic SB, Vukadinov J, et al. Leptospirosis distribution related to freshwater habitats in the Vojvodina region (Republic of Serbia). Sci China C Life Sci. 2009;52(10):965-971.

89. Suwanpakdee S, Kaewkungwal J, White LJ, et al. Spatio-temporal patterns of leptospirosis in Thailand: is flooding a risk factor? Epidemiol Infect. 2015;143(10):2106-2115.

90. Ivanova S, Herbreteau V, Blasdell K, et al. Leptospira and rodents in Cambodia: environmental determinants of infection. Am J Trop Med Hyg. 2012;86(6):1032-1038.

91. Robertson C, Nelson TA, Stephen C. Spatial epidemiology of suspected clinical leptospirosis in Sri Lanka. Epidemiol Infect. 2012;140(4):731-743.

92. Sanchez-Montes S, Espinosa-Martinez DV, Rios-Munoz CA, BerzunzaCruz M, Becker I. Leptospirosis in Mexico: epidemiology and potential distribution of human cases. PLoS One. 2015;10(7):e0133720.

93. Lau CL, Skelly C, Dohnt M, Smythe LD. The emergence of Leptospira borgpetersenii serovar Arborea in Queensland, Australia, 2001 to 2013. BMC Infect Dis. 2015;15:230.

94. Lau CL, Clements ACA, Skelly C, Dobson AJ, Smythe LD, Weinstein P. Leptospirosis in American Samoa - estimating and mapping risk using environmental data. PLoS Negl Trop Dis. 2012;6(5):e1669.

95. Schneider MC, Najera P, Aldighieri S, et al. Leptospirosis outbreaks in Nicaragua: identifying critical areas and exploring drivers for evidencebased planning. Int J Environ Res Public Health. 2012;9(11):3883-3910.

96. Barcellos C, Sabroza PC. The place behind the case: leptospirosis risks and associated environmental conditions in a flood-related outbreak in Rio de Janeiro. Cad Saude Publica. 2001;17(Suppl):59-67.

97. Fonzar UJ, Langoni H. Geographic analysis on the occurrence of human and canine leptospirosis in the city of Maringa, state of Parana, Brazil. Rev Soc Bras Med Trop. 2012;45(1):100-105.

98. Gracie R, Barcellos C, Magalhães M, Souza-Santos R, Guimarães Barrocas PR. Geographical scale effects on the analysis of leptospirosis determinants. Int J Environ Res Public Health. 2014;11(10):10366-10383.

99. Hagan JE, Moraga P, Costa F, et al. Spatiotemporal determinants of urban leptospirosis transmission: four-year prospective cohort study of slum residents in Brazil. PLoS Negl Trop Dis. 2016;10(1):e0004275.

100. Thornley CN, Baker MG, Weinstein P, Maas EW. Changing epidemiology of human leptospirosis in New Zealand. Epidemiol Infect. 2002;128(1):29-36. 
101. Dreyfus A, Benschop J, Collins-Emerson J, Wilson P, Baker MG, Heuer C. Sero-prevalence and risk factors for leptospirosis in abattoir workers in New Zealand. Int J Environ Res Public Health. 2014;11(2): 1756-1775.

102. Adler B. Vaccines against leptospirosis. Curr Top Microbiol Immunol. 2015;387:251-272.

103. Ellis WA. Animal leptospirosis. Current topics in microbiology and immunology. 2015;387:99-137.

104. Vallee E, Ridler AL, Heuer C, Collins-Emerson JM, Benschop J, Wilson PR. Effectiveness of a commercial leptospiral vaccine on urinary shedding in naturally exposed sheep in New Zealand. Vaccine. In press 2016.

105. Vallee E, Heuer C, Collins-Emerson JM, Benschop J, Wilson PR. Serological patterns, antibody half-life and shedding in urine of Leptospira spp. in naturally exposed sheep. $N$ Z Vet J. 2015;63(6):301-312.

106. Takafuji ET, Kirkpatrick JW, Miller RN, et al. An efficacy trial of doxycycline chemoprophylaxis against leptospirosis. New Engl J Med. 1984;310(8):497-500.

107. Sejvar J, Bancroft E, Winthrop K, et al. Leptospirosis in "EcoChallenge" athletes, Malaysian Borneo, 2000. Emerg Infect Dis. 2003;9(6):702-707.

108. Belmaker I, Alkan M, Barnea A, Dukhan L, Yitzhaki S, Gross E. Risk of transmission of leptospirosis from infected cattle to dairy workers in southern Israel. Isr Med Assoc J. 2004;6(1):24-27.

109. Sehgal SC, Sugunan AP, Murhekar MV, Sharma S, Vijayachari P. Randomized controlled trial of doxycycline prophylaxis against leptospirosis in an endemic area. Int J Antimicrob Agents. 2000;13(4): 249-255.

110. Dechet AM, Parsons M, Rambaran M, et al. Leptospirosis outbreak following severe flooding: a rapid assessment and mass prophylaxis campaign; Guyana, January-February 2005. PLoS One. 2012; 7(7):e39672.

111. Brett-Major DM, Lipnick RJ. Antibiotic prophylaxis for leptospirosis. Cochrane Database Syst Rev. 2009;3:CD007342.

112. Dufour B, Moutou F, Hattenberger AM, Rodhain F. Global change: impact, management, risk approach and health measures - the case of Europe. Rev Sci Tech. 2008;27(2):529-550.
113. Tsegay K, Potts AD, Aklilu N, Lötter C, Gummow B. Circulating serovars of Leptospira in cart horses of central and southern Ethiopia and associated risk factors. Prev Vet Med. 2016;125:106-115.

114. Zhang HL, Mnzava KW, Mitchell ST, et al. Mixed methods survey of zoonotic disease awareness and practice among animal and human healthcare providers in Moshi, Tanzania. PLoS Negl Trop Dis. 2016;10(3):e0004476.

115. Jobbins SE, Alexander KA. Evidence of Leptospira sp. infection among a diversity of African wildlife species: beyond the usual suspects. Trans R Soc Trop Med Hyg. 2015;109(5):349-351.

116. Chipwaza B, Mhamphi GG, Ngatunga SD, et al. Prevalence of bacterial febrile illnesses in children in Kilosa District, Tanzania. PLoS Negl Trop Dis. 2015;9(5):e0003750.

117. Allan KJ, Biggs HM, Halliday JE, et al. Epidemiology of leptospirosis in Africa: a systematic review of a neglected zoonosis and a paradigm for 'one health' in Africa. PLoS Negl Trop Dis. 2015;9(9):e0003899.

118. Allan KJ, Halliday JE, Cleaveland S. Renewing the momentum for leptospirosis research in Africa. Trans $R$ Soc Trop Med Hyg. 2015;109(10):605-606.

119. Mgode GF, Machang'u RS, Mhamphi GG, et al. Leptospira serovars for diagnosis of leptospirosis in humans and animals in Africa: common Leptospira isolates and reservoir hosts. PLoS Negl Trop Dis. 2015;9(12):e0004251.

120. Bertherat E, Mueller MJ, Shako JC, Picardeau M. Discovery of a leptospirosis cluster amidst a pneumonic plague outbreak in a miners' cAMP in the democratic republic of the congo. Int J Environ Res Public Health. 2014;11(2):1824-1833.

121. de Vries SG, Visser BJ, Nagel IM, Goris MG, Hartskeerl RA, Grobusch MP. Leptospirosis in Sub-Saharan Africa: a systematic review. Int J Infect Dis. 2014;28:47-64.

122. Hartskeerl RA. International Leptospirosis Society: objectives and achievements. Rev Cubana Med Trop. 2005;57(1):7-10.

123. Durski KN, Jancloes M, Chowdhary T, Bertherat E. A global, multidisciplinary, multi-sectorial initiative to combat leptospirosis: Global Leptospirosis Environmental Action Network (GLEAN). Int J Envir Res Public Health. 2014;11(6):6000-6008.

124. Turner LH. Leptospirosis. I. Trans R Soc Trop Med Hyg. 1967;61(6): 842-855.
Research and Reports in Tropical Medicine

\section{Publish your work in this journal}

Research and Reports in Tropical Medicine is an international, peerreviewed, open access journal publishing original research, case reports, editorials, reviews and commentaries on all areas of tropical medicine, including: Diseases and medicine in tropical regions; Entomology; Epidemiology; Health economics issues; Infectious disease; Laboratory

\section{Dovepress}

science and new technology in tropical medicine; Parasitology; Public health medicine/health care policy in tropical regions; and Microbiology The manuscript management system is completely online and includes a very quick and fair peer-review system. Visit http://www.dovepress. com/testimonials.php to read real quotes from published authors. 